\title{
Short- and long-term outcomes of endoscopic submucosal dissection for early gastric cancer in elderly patients aged 75 years and older
}

\author{
Tetsuya Sumiyoshi ${ }^{1} \cdot$ Hitoshi Kondo $^{1} \cdot$ Ryoji Fujii $^{1} \cdot$ Takeyoshi Minagawa $^{1} \cdot$ \\ Shinya Fujie ${ }^{1}$. Tomohiro Kimura ${ }^{1} \cdot$ Hideyuki Ihara $^{1} \cdot$ Naohito Yoshizaki $^{1}$. \\ Michiaki Hirayama $^{1} \cdot$ Yumiko Oyamada $^{2} \cdot$ Shunichi Okushiba $^{3}$
}

Received: 23 February 2016/Accepted: 2 August 2016/Published online: 19 August 2016

(c) The International Gastric Cancer Association and The Japanese Gastric Cancer Association 2016

\begin{abstract}
Background Only a few studies have reported long-term outcomes for endoscopic submucosal dissection (ESD) of early gastric cancer (EGC) in elderly patients. The aim of this study was to evaluate the efficacy of ESD for EGC in elderly patients $\geq 75$ years with respect to both short- and long-term outcomes.

Methods We reviewed the clinical data of elderly patients $\geq 75$ years who had undergone ESD for EGC at Tonan Hospital from January 2003 to May 2010.

Results A total of 177 consecutive patients, including 145 with curative resection (CR) and 32 with noncurative resection (non-CR), were examined. Of the 32 patients with non-CR, 15 underwent additional surgery, and lymph node metastases were found in 3 patients. The remaining 17 patients were followed without additional surgery because of advanced age or poor general condition. Procedure-related complications, such as post-ESD bleeding, perforation and pneumonia, were within the acceptable range. The 5-year survival rates of patients with CR, those with additional surgery after non-CR, and those without additional surgery after non-CR were 84.6, 73.3, and $58.8 \%$, respectively. No deaths were attributable to the original gastric cancer; patients succumbed to other illnesses, including malignancy and respiratory disease.
\end{abstract}

Tetsuya Sumiyoshi

t-sumiyoshi@tonan.gr.jp

1 Department of Gastroenterology, Tonan Hospital, Kita 1, Nishi 6, Chuo-ku, Sapporo, Hokkaido 060-0001, Japan

2 Department of Pathology, Tonan Hospital, Kita 1, Nishi 6, Chuo-ku, Sapporo, Hokkaido 060-0001, Japan

3 Department of Surgery, Tonan Hospital, Kita 1, Nishi 6, Chuo-ku, Sapporo, Hokkaido 060-0001, Japan
Conclusions In elderly patients, ESD is an acceptable treatment for EGC in terms of both short- and longterm outcomes. Careful clinical assessment of elderly patients is necessary before ESD. After ESD, medical follow-up is important so that other malignancies and diseases that affect the elderly are not overlooked.

Keywords Early gastric cancer - Endoscopic submucosal dissection (ESD) · Elderly

\section{Introduction}

The Japanese population is aging, and according to the World Health Organization's 2013 World Health Reports, the average life expectancy has increased to 86 years for women and 79 years for men [1]. Consequently, the number of elderly patients diagnosed with early gastric cancer (EGC) is steadily increasing. Many elderly patients not only have various comorbidities but also exhibit an age-related decline in physical performance. Therefore, a less invasive treatment is desirable for these elderly patients with EGC.

Endoscopic submucosal dissection (ESD) is a minimally invasive treatment for EGC when performed according to the absolute or expanded indications [2]. Many studies have reported good results with respect to the short- and long-term outcomes of ESD [3-11]. However, with regard to elderly patients, there have been only a few reports on long-term outcomes, with median follow-up periods of $<4$ years [12, 13]; several favorable short-term outcomes have been published [14-18]. EGC generally grows slowly, and the cumulative 5-year risk for progression to an advanced stage has been reported to be $63 \%$ [19]. Therefore, a longer follow-up period is necessary to evaluate the usefulness of ESD for elderly patients (although 
they have a limited life expectancy). Consequently, our aim was to evaluate the efficacy of ESD for EGC in elderly patients $\geq 75$ years who were followed for $\geq 5$ years after ESD with respect to both short- and long-term outcomes.

\section{Patients and methods}

\section{Patients}

A total of 485 consecutive patients with 572 EGCs underwent ESD at Tonan Hospital from January 2003 to May 2010. We defined elderly patients as those $\geq 75$ years. Among the 485 patients, 184 (38.0\%) with 220 EGCs were elderly. Of these 184 patients, 5 with EGC who did not meet the preoperative criteria for ESD by endoscopic diagnosis and 2 missing patients were excluded.

We retrospectively analyzed the medical records of the remaining 177 patients with 209 EGCs to assess the longterm outcomes of $\geq 5$ years after ESD; also included were patients who died for any reasons within 5 years after ESD (Fig. 1). The survival information of patients who had not regularly attended our hospital was retrieved by contacting either their family members or their physicians. Informed written consent was obtained from either the patients or their families before ESD. This study was conducted in accordance with the Declaration of Helsinki and was approved by the Institutional Review Board of the Tonan Hospital.

\section{Indications for ESD}

In general, ESD was performed for EGCs that clinically fulfilled the absolute or expanded indication for endoscopic resection according to the Japanese Gastric Cancer Treatment Guidelines of 2010 [2]. In addition, the eligibility criteria for
ESD based on physical condition were principally as follows: (1) Eastern Cooperative Oncology Group performance status (PS) [20] of 0,1 , or 2; (2) no comorbidity or comorbidities that could be well managed; (3) no concomitant malignancies in other organs determined by blood testing, chest and abdominal computed tomography (CT), and colonoscopy that could affect the prognosis of patients. However, ESD was performed for EGC regardless of PS or comorbidities if the patients or their families strongly desired the treatment.

\section{Clinicopathological characteristics}

The location and macroscopic type of EGC were endoscopically evaluated. The location of EGC was divided into the upper, middle, and lower thirds of the stomach; the macroscopic type of EGC was classified according to the Japanese Classification of Gastric Carcinoma [21].

\section{Histopathological evaluation}

The resected specimens were examined pathologically with regard to tumor size, histological type, depth of invasion, lymphovascular involvement, and tumor involvement along the lateral and vertical margins. The curability of ESD was then classified as either curative or noncurative resection on the basis of histological assessment [2]. Curative resection (CR) was defined as en bloc resection with margins free of tumor and any of the following curability criteria: (1) differentiated intramucosal adenocarcinoma without ulcer findings irrespective of tumor size and without lymphovascular invasion; (2) differentiated intramucosal adenocarcinoma with ulcers $\leq 3 \mathrm{~cm}$ in size and without lymphovascular invasion; (3) undifferentiated intramucosal adenocarcinoma without ulcer findings $\leq 2 \mathrm{~cm}$ in size and without lymphovascular invasion; (4)

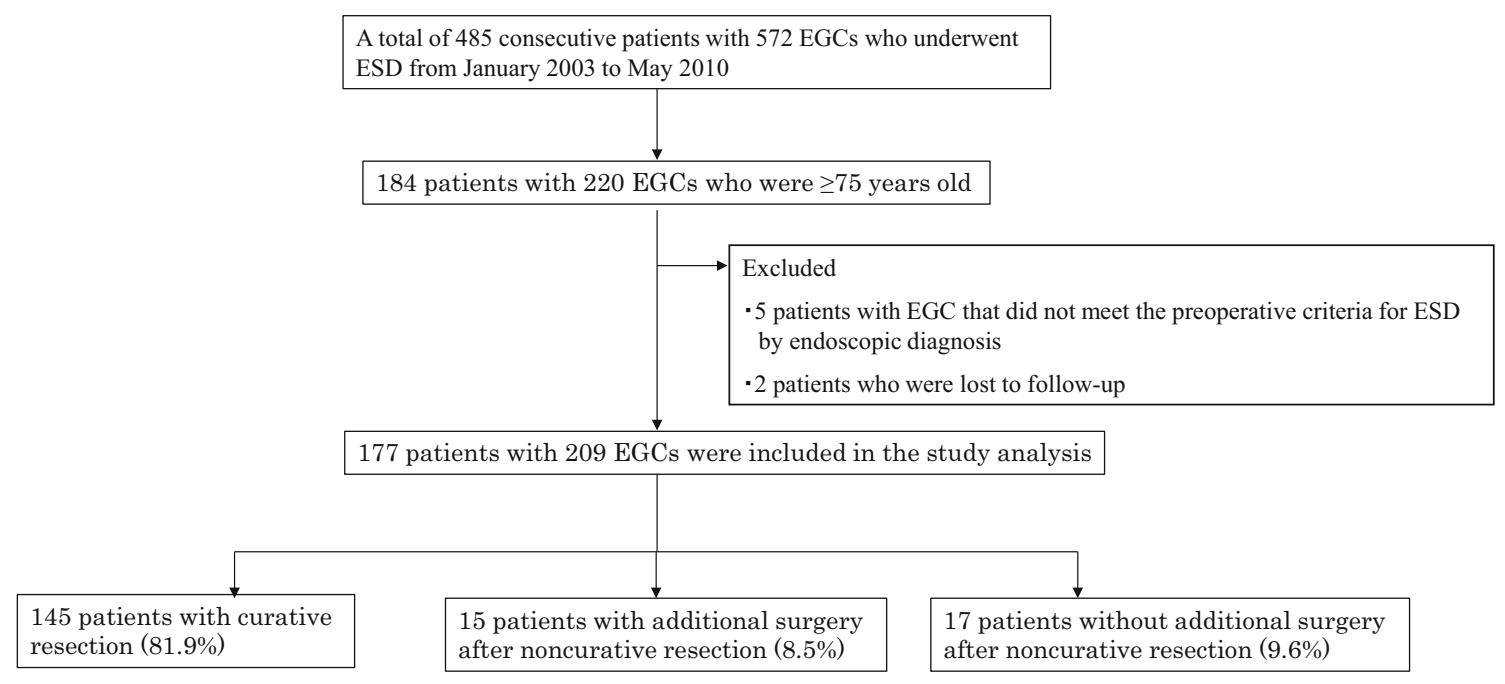

Fig. 1 Patient selection flow diagram for the study 
differentiated adenocarcinoma with minute submucosal invasion $(\mathrm{SM} 1) \leq 3 \mathrm{~cm}$ in size and without lymphovascular invasion. Noncurative resection (non-CR) was defined as resection that did not meet the curability criteria above and/ or that had margins positive for tumor or had difficulty in the histological evaluation. In addition, patients with multifocal EGC were classified as noncurative if they had any EGC site with a non-CR.

\section{Short-term outcomes}

The short-term outcomes were evaluated on the basis of curability and complications. Post-ESD bleeding was defined as bleeding from the ulcer with occurrence of hematemesis and/ or melena after the procedure that required a hemostatic treatment, such as endoscopic clipping or coagulation by hemostatic forceps. Perforation was diagnosed endoscopically during the procedure. Delayed perforation was defined as perforation that developed after the procedure and confirmed endoscopically or detected as pneumoperitoneum by either abdominal computed tomography (CT) or roentgenography. Pneumonia after the procedure was diagnosed by either chest CT or roentgenography. Procedure-related mortality was defined as any death due to a complication.

\section{Long-term outcomes}

Patients were divided into three groups: those with CR, those with additional surgery after non-CR, and those without additional surgery after non-CR. The survival rates of these three separate groups were compared with the expected survival rate of the general population, as calculated by using the life tables for the Japanese population matched by the sex and age of the elderly patients involved in this study [22].

\section{Statistical analysis}

The significance of differences in the patients' characteristics and clinicopathological findings was analyzed using Fisher's exact test, the chi-square test, or one-factor ANOVA as appropriate. Survival rates from the date of ESD were calculated by using the Kaplan-Meier method, and the logrank test was used to compare survival. A value of $p<0.05$ was considered to indicate statistical significance.

\section{Results}

\section{Clinicopathological characteristics}

The patient characteristics are summarized in Table 1. The mean patient age was 79.7 years (range 75-91 years), and
Table 1 Patient characteristics $(n=177)$

\begin{tabular}{ll}
\hline Mean age (range) (years) & $79.7(75-91)$ \\
Sex ratio (M:F) & $118: 59$ \\
Comorbid disease & \\
Hypertension & $108(61.0 \%)$ \\
Cardiovascular disease & $36(20.3 \%)$ \\
Diabetes & $25(14.1 \%)$ \\
Previous cerebrovascular event & $13(7.3 \%)$ \\
Respiratory disease & $10(5.6 \%)$ \\
Other previously treated malignancy & $44(24.9 \%)$ \\
Having $\geq 1$ comorbidity & $132(74.6 \%)$ \\
Having $\geq 2$ comorbidities & $72(40.7 \%)$ \\
Antithrombotic agents use & $42(23.7 \%)$ \\
Performance status & \\
$0-1 / 2 / 3 / 4$ & $152 / 19 / 6 / 0$ \\
\hline
\end{tabular}

the male/female ratio was 2:1 (118:59). One hundred thirtytwo patients $(74.6 \%)$ had at least one comorbidity with medical treatment, and 72 patients $(40.7 \%)$ had two or more comorbidities. Antithrombotic agents were administered to 42 patients $(23.7 \%)$ for cardiovascular disease and/or prevention of cerebral infarction. The PS score was 0-1 in 152 patients, 2 in 19 patients, and 3 in 6 patients.

Table 2 shows the histopathological findings of the resected lesions. Seventeen patients had multiple simultaneous EGCs at the time of ESD.

\section{Short-term outcomes (Table 3)}

CR was achieved in 145 patients (81.9\%). Of the 32 patients with non-CR, 15 underwent additional surgery, and lymph node metastases were detected pathologically in 3 . The remainder were followed because of their advanced age or poor general condition (Fig. 1).

Post-ESD bleeding and perforation rates were 6.7 and $4.8 \%$, respectively, and pneumonia occurred in $1.7 \%$ of the patients. All of these complications were treated with conservative therapy. A patient with CR underwent emergency surgery for peritonitis caused by delayed perforation, but the patient died of multiorgan failure on the 32 nd day after ESD.

\section{Long-term outcomes}

The median follow-up period was 79 months (range 1-143 months) in patients with CR, 73 months (range 26-141 months) in those with additional surgery after nonCR, and 62 months (range 9-120 months) in those without additional surgery after non-CR.

Patient characteristics in the three groups are summarized in Table 4. There were no significant differences among the 
Table 2 Lesion characteristics $(n=209)$

\begin{tabular}{ll}
\hline Location & \\
Upper third & $58(27.8 \%)$ \\
Middle third & $62(29.7 \%)$ \\
Lower third & $89(42.6 \%)$ \\
Macroscopic type & $15(7.2 \%)$ \\
Type 0-I & $82(39.2 \%)$ \\
Type 0-IIa & $3(1.4 \%)$ \\
Type 0-IIb & $89(42.6 \%)$ \\
Type 0-IIc & $10(4.8 \%)$ \\
Type 0-I + IIa & $10(4.8 \%)$ \\
Type 0-IIa + IIc & $22.0 \pm 15.9$ \\
Mean (SD) tumor size (mm) & \\
Histological type & $204(97.6 \%)$ \\
Differentiated type & $5(2.4 \%)$ \\
Undifferentiated type & $172(82.3 \%)$ \\
Depth of invasion & \\
Mucosa & $20(9.6 \%)$ \\
Submucosa & $17(8.1 \%)$ \\
SM1 & \\
SM2 & \\
\hline SM was classified as SMI and SM2. SM1 was defined as cancer \\
invasion of $<500 \mu$ m from the muscularis mucosae, \\
was defined as invasion that was 500 $\mu$ m or deeper \\
\end{tabular}

Table 3 Short-term outcomes of ESD

\begin{tabular}{lc}
\hline & $\begin{array}{l}\text { Number of patients }(n=177) \\
\text { and tumors }(n=209)\end{array}$ \\
\hline Curability & $145(81.9 \%)$ \\
Curative resection & $32(18.1 \%)$ \\
Noncurative resection & \\
Complications & $14(6.7 \%)$ \\
Post-ESD bleeding & $10(4.8 \%)$ \\
Perforation & $3(1.7 \%)$ \\
Pneumonia & $1(0.6 \%)$ \\
Delayed perforation & $1(0.6 \%)^{\mathrm{a}}$ \\
Procedure-related death &
\end{tabular}

${ }^{a}$ One patient died of delayed perforation

three groups with respect to the patients' background factors, such as age, sex, comorbidities, or PS score. Lymphovascular invasion, which is associated with a high risk of lymph node metastasis [23], was more frequent in the patients with additional surgery after non-CR than in those without additional surgery after non-CR $(p=0.015)$. The frequency of massive submucosal invasion (SM2) tended to be higher in the patients with additional surgery after non-CR than in those without additional surgery after non-CR, but the difference was not statistically significant $(p=0.08)$.
The 5-year survival rates in the patients with CR, those with additional surgery after non-CR, and those without additional surgery after non-CR were $84.6,73.3$, and $58.8 \%$, respectively (Fig. 2). The overall survival rate of the patients with CR was superior to that of the patients without additional surgery after non-CR $(p=0.0001)$. There was no significant difference in the overall survival rates between the patients with CR and those with additional surgery after non-CR $(p=0.11)$, nor was there a significant difference in the overall survival rates between the patients with additional surgery after non-CR and those without additional surgery after non-CR ( $p=0.19)$. In addition, the 5-year survival rate of the patients with CR was better than the expected survival rate $(77.5 \%)$, and the 5-year survival rate of those with additional surgery after non-CR was similar to the expected survival rate. In contrast, the 5-year survival rate of the patients without additional surgery after non-CR was lower than the expected survival rate.

A total of 62 patients died during the follow-up period. The causes of death in the three groups are shown in Table 5. The most frequent causes of death were other malignancies (20 patients) and respiratory diseases (16 patients), although 1 patient died of metachronous advanced gastric cancer.

\section{Discussion}

In aging societies, there is an important opportunity to decide on the optimal treatment option for elderly patients with EGC. Although ESD is generally accepted as a safe treatment, it carries some risks for elderly patients with comorbidities because of the long procedure time (with deep sedation) and procedure-related complications [24-28]. Therefore, in considering the indications for ESD in elderly patients, we must keep in mind their general condition, including the severity of comorbidities and PS score. We principally performed ESD in elderly patients whose comorbidities were well managed and whose PS scores were $\leq 2$, although most patients $(74.6 \%)$ had at least one comorbidity, and some of them (3.4\%) had a PS of 3 in the present study.

Regarding short-term outcomes, a CR rate of $81.9 \%$ appears to be excellent, and complication rates approximated those of previous reports [13, 15-17, 28, 29]. However, we had one ESD-related death from delayed perforation in a PS 3 patient. This was the first case of an ESD-related death at our hospital, which suggested that procedure-related complications are potentially fatal in elderly patients.

Regarding long-term outcomes, our data demonstrate that the prognosis after ESD is acceptable in elderly patients with CR and in those with additional surgery after 
Table 4 Patient characteristics among the three groups

\begin{tabular}{|c|c|c|c|c|}
\hline & $\begin{array}{l}\text { Curative resection } \\
(n=145)\end{array}$ & $\begin{array}{l}\text { Additional surgery after } \\
\text { noncurative resection } \\
(n=15)\end{array}$ & $\begin{array}{l}\text { Noncurative resection without } \\
\text { additional surgery } \\
(n=17)\end{array}$ & $P$ value \\
\hline Mean age (range) (years) & $79.8(75-91)$ & $78.7(75-86)$ & $79.3(75-90)$ & $n . s$ \\
\hline Sex ratio $(\mathrm{M}: \mathrm{F})$ & $91: 54$ & $13: 2$ & $14: 3$ & $n . s$ \\
\hline \multicolumn{5}{|l|}{ Comorbid disease } \\
\hline Hypertension & 88 & 9 & 11 & $n . s$ \\
\hline Cardiovascular disease & 28 & 3 & 5 & $n . s$ \\
\hline Previous cerebrovascular event & 10 & 1 & 2 & $n . s$ \\
\hline Respiratory disease & 8 & 2 & 0 & $n . s$ \\
\hline Diabetes & 23 & 2 & 0 & $n . s$ \\
\hline Other malignancy previously treated & 33 & 5 & 6 & $n . s$ \\
\hline Having 2 or more comorbidities & 58 & 7 & 7 & $n s$ \\
\hline Antithrombotic agents use & 33 & 4 & 5 & $n . s$ \\
\hline Performance status score $\geq 2$ & 21 & 0 & 4 & $n . s$ \\
\hline \multicolumn{5}{|l|}{ Depth of invasion } \\
\hline Mucosa & 135 & 1 & 8 & $P=0.014^{\mathrm{a}}$ \\
\hline SM1 & 10 & 4 & 3 & $n . s^{a}$ \\
\hline SM2 & 0 & 10 & 6 & $P=0.08^{\mathrm{a}}$ \\
\hline \multicolumn{5}{|l|}{ Lymphovascular involvement } \\
\hline Presence & 0 & 8 & 2 & $P=0.015^{\mathrm{a}}$ \\
\hline
\end{tabular}

a The significance of differences was analyzed between the patients with additional surgery after noncurative resection and those without additional surgery after noncurative resection

Fig. 2 Overall survival curve for each group and expected survival. The 5-year survival rates of the patients with curative resection, those with additional surgery after noncurative resection, and those without additional surgery after noncurative resection were 84.6, 73.3 , and $58.8 \%$, respectively

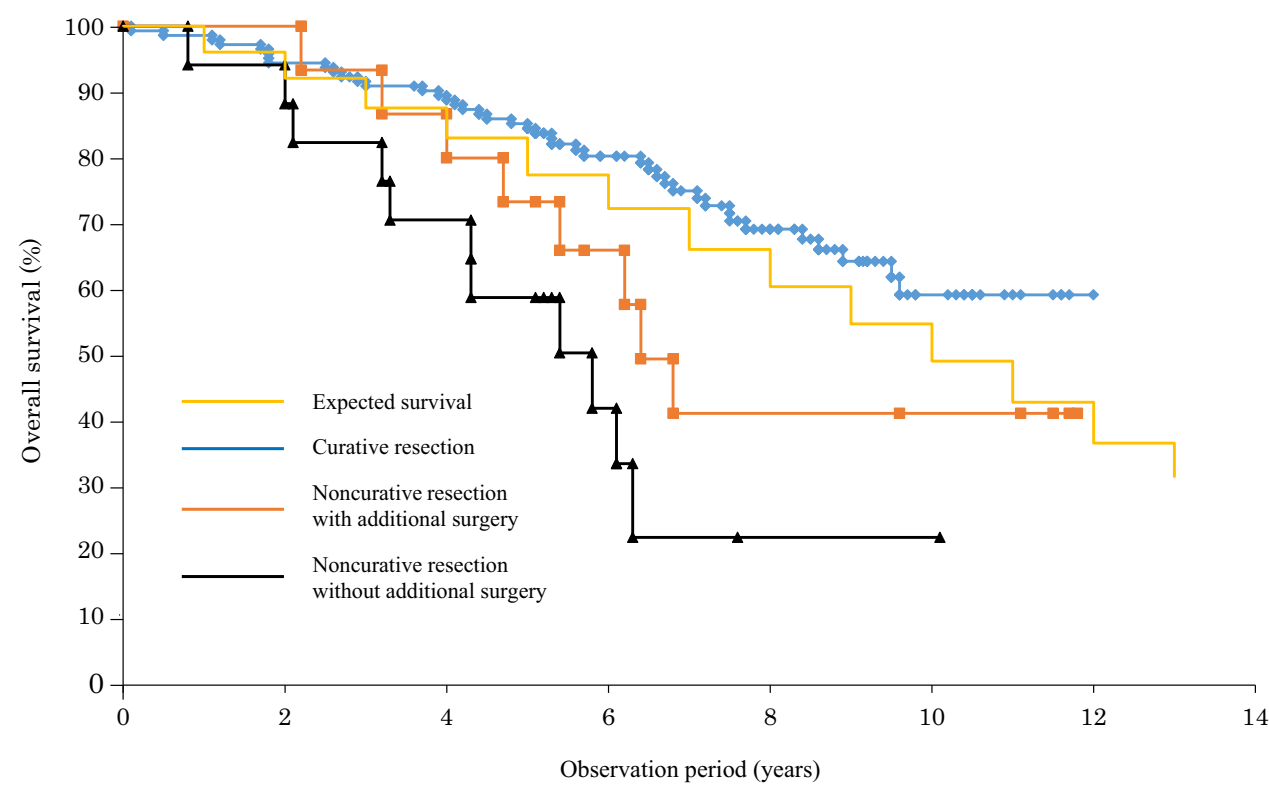

non-CR when considering the expected survival rate of the general population. Consequently, curative ESD may contribute to the increase in life expectancy, and additional surgery should be considered if an elderly patient is in good health; the pathology in 3 of 15 patients with non-CR revealed lymph node metastases. Conversely, elderly patients without additional surgery after non-CR had the worst prognosis, a finding that is similar to those of previous reports [12, 13], although there was no significant difference in prognoses between elderly patients without additional surgery after non-CR and those with additional surgery because of the small number of noncurative cases. 
Table 5 Distribution of causes of death

\begin{tabular}{llll}
\hline & $\begin{array}{l}\text { Curative } \\
\text { resection } \\
(n=145)\end{array}$ & $\begin{array}{l}\text { Additional surgery after } \\
\text { noncurative resection } \\
(n=15)\end{array}$ & $\begin{array}{l}\text { Noncurative resection without } \\
\text { additional surgery } \\
(n=17)\end{array}$ \\
\hline $\begin{array}{l}\text { Number of deaths } \\
\text { Cause of death }\end{array}$ & 43 & 8 & 11 \\
Gastric cancer & 0 & 0 & $1^{\mathrm{a}}$ \\
Other alignancy & 15 & 3 & 2 \\
Cardiovascular disease & 1 & 2 & 2 \\
Cerebrovascular disease & 2 & 0 & 1 \\
Respiratory disease & 10 & 3 & 3 \\
Other causes & 11 & 0 & 1 \\
Procedure-related death & 1 & 0 & 0 \\
Unknown & 3 & 0 & 1 \\
\hline
\end{tabular}

${ }^{a}$ Metachronous gastric cancer
However, none of the patients in this group died of recurrent gastric cancer, and most succumbed to other diseases. Although there were no significant differences among the three groups with respect to the patients' backgrounds (including comorbidities or PS score), many patients in this non-CR group might have had potentially serious comorbidities and/or age-related physical decline, had pre-emptive surgery, and subsequently died of other causes, including non-gastric cancer, cardiovascular disease, or respiratory disease within 5 years after ESD. Moreover, this cohort of patients may include those who were neither as healthy nor as high in socioeconomic level as those who could attend a highly specialized treatment center $[12,13]$, which resulted in a lower 5-year survival rate than expected. Nevertheless, some of these patients survived for a long time, including $22.4 \%$ with a 10 -year survival rate; providing local control by ESD is potentially significant even for this selection of patients.

In the other two groups of our study, there were also no recurrent gastric cancer deaths; most causes of death were other malignancies or respiratory disease. These findings, including the poor prognosis of elderly patients without additional surgery after non-CR, suggest that the indications for ESD in elderly patients with EGC should be decided on the basis of not only lesion criteria but also of general condition, such as PS, organ function, severity of comorbidities, and presence or absence of other malignancies that could affect the prognosis of the elderly. Moreover, the management of comorbidities and the follow-up for other malignancies after ESD would be necessary for long-term survival.

With regard to the limitations of this study, the results were obtained at a single center, and the number of cases was relatively small (specifically patients with non-CR). Despite these limitations, we believe that the long-term outcome of ESD for the treatment of EGC in elderly patients (followed over a period of 5 years after ESD) is meaningful. We hope that a retrospective multicenter study incorporating a large number of patients is conducted in the future for long-term investigation after ESD because a prospective randomized study raises ethical concerns in patients with non-CR.

In conclusion, ESD may be considered to be an acceptable treatment for EGC in elderly patients with regard to both short-and long-term outcomes. Curative ESD may increase the life expectancy of elderly patients, and additional surgery after noncurative ESD may be recommended if an elderly patient is in good condition. The indications for ESD in elderly patients with EGC should be decided on the basis of not only lesion criteria but also of careful assessment of the patient's general condition. In addition, after ESD, close medical follow-up is necessary so that other malignancies and diseases that affect the elderly are not overlooked.

Acknowledgments We thank Dr. Kei Doi (Northeast Radiology, Inc.) for editing this paper.

\section{Compliance with ethical standards}

Conflict of interest The authors declare that they have no conflicts of interest.

Ethical standards All procedures followed were in accordance with the ethical standards of the responsible committee on human experimentation (institutional and national) and with the Helsinki Declaration of 1964 and later versions. Informed consent or a substitute for it was obtained from all patients for being included in the study.

\section{References}

1. World Health Organization. Global health indicators. Life expectancy and mortality. 2016. http://www.who.int/gho/publications/ world_health_statistics/EN_WHS2013_Full.pdf?ua=1. Accessed 19 Feb 2016. 
2. Japanese Gastric Cancer Association. Japanese gastric cancer treatment guidelines 2010 (Ver. 3). Gastric Cancer. 2011;14:113-23.

3. Ono H, Kondo H, Gotoda T, Shirao K, Yamaguchi H, Saito D, et al. Endoscopic mucosal resection for treatment of early gastric cancer. Gut. 2001;48:225-9.

4. Abe N, Yamaguchi Y, Takeuchi H, Izumisato Y, Yanagida O, Masaki T, et al. Key factors for successful en bloc endoscopic submucosal dissection of early stage gastric cancer using an insulation-tipped diathermic knife. Hepatogastroenterology. 2006;53:639-42.

5. Oda I, Saito D, Tada M, Iishi H, Tanabe S, Oyama T, et al. A multicenter retrospective study of endoscopic resection for early gastric cancer. Gastric Cancer. 2006;9:162-70.

6. Gotoda T. Endoscopic resection of early gastric cancer. Gastric Cancer. 2007;10:1-11.

7. Chung IK, Lee JH, Lee SH, Kim SJ, Cho JY, Cho WY, et al. Therapeutic outcomes in 1000 cases of endoscopic submucosal dissection for early gastric neoplasms: Korean ESD study Group multicenter study. Gastrointest Endosc. 2009;69:1228-35.

8. Isomoto H, Shikuwa S, Yamaguchi N, Fukuda E, Ikeda K, Nishiyama $\mathrm{H}$, et al. Endoscopic submucosal dissection for early gastric cancer: a large-scale feasibility study. Gut. 2009;58:33-6.

9. Gotoda T, Iwasaki M, Kusano C, Seewald S, Oda I. Endoscopic resection of early gastric cancer treated by guideline and expanded National Cancer Centre criteria. $\mathrm{Br}$ J Surg. 2010;97:868-71.

10. Oda I, Oyama T, Abe S, Ohnita K, Kosaka T, Hirasawa K, et al. Preliminary results of multicenter questionnaire study on longterm outcomes of curative endoscopic submucosal dissection for early gastric cancer. Dig Endosc. 2005;17:54-8.

11. Kosaka T, Endo M, Toya Y, Abiko Y, Kudara N, Inomata M, et al. Long-term outcomes of endoscopic submucosal dissection for early gastric cancer: a single-center retrospective study. Dig Endosc. 2014;26:183-91.

12. Kusano C, Iwasaki M, Kaltenbach T, Conlin A, Oda I, Gotoda T. Should elderly patients undergo additional surgery after non-curative endoscopic resection for early gastric cancer? Long-term comparative outcomes. Am J Gastroenterol. 2011;106:1064-9.

13. Abe N, Gotoda T, Hirasawa T, Hoteya S, Ishido K, Ida Y, et al. Multicenter study of the long-term outcomes of endoscopic submucosal dissection for early gastric cancer in patients 80 years of age or older. Gastric Cancer. 2012;15:70-5.

14. Tokioka S, Umegaki E, Murano M, Takeuchi N, Takeuchi T, Kawakami K, et al. Utility and problems of endoscopic submucosal dissection for early gastric cancer in elderly patients. J Gastroenterol Hepatol. 2012;27(suppl 3):63-9.

15. Hirasaki S, Tanimizu M, Nasu J, Shinji T, Koide N. Treatment of elderly patients with early gastric cancer by endoscopic submucosal dissection using an insulated-tip diathermic knife. Intern Med. 2005;44:1033-8.

16. Kakushima N, Fujishiro M, Kodashima S, Muraki Y, Tateishi A, Yahagi N, et al. Technical feasibility of endoscopic submucosal dissection for gastric neoplasms in the elderly Japanese population. J Gastroenterol Hepatol. 2007;22:311-4.

17. Toyokawa T, Fujita I, Morikawa T, Okamoto A, Miyasaka R, Watanabe K, et al. Clinical outcomes of ESD for early gastric neoplasms in elderly patients. Eur J Clin Invest. 2011;41:474-8.

18. Isomoto H, Ohnita K, Yamaguchi N, Fukuda E, Ikeda K, Nishiyama $\mathrm{H}$, et al. Clinical outcomes of endoscopic submucosal dissection in elderly patients with early gastric cancer. Eur J Gastroenterol Hepatol. 2010;22:311-7.

19. Tsukuma H, Oshima A, Narahara H, Morii T. Natural history of early gastric cancer: a non-concurrent, long term, follow up study. Gut. 2000;47:618-21.

20. Oken MM, Creech RH, Tormey DC, Horton J, Davis TE, McFadden ET, et al. Toxicity and response criteria of the Eastern Cooperative Oncology Group. Am J Clin Oncol. 1982;5:649-55.

21. Japanese Gastric Cancer Association. Japanese classification of gastric carcinoma. 3rd English edition. Gastric Cancer. 2011;14:101-12.

22. Statics and Information Department, Minister's Secretariat, Ministry of Health and Welfare of Japan. The abridged life table for Japan. 2016. http://www.mhlw.go.jp/english/database/ db-hw/lifetb14/index.html. Accessed 7 May 2016.

23. Gotoda T, Sasako M, Ono H, Katai H, Sano T, Shimoda T. Evaluation of necessity for gastrectomy with lymph node dissection patients with submucosal invasive gastric cancer. $\mathrm{Br} \mathrm{J}$ Surg. 2001;88:444-9.

24. Park CH, Min JH, Yoo Y, Kim H, Joh DH, Jo JH, et al. Sedation methods can determine performance of endoscopic submucosal dissection in patients with gastric neoplasia. Surg Endosc. 2013;27:2760-7.

25. Gotoda T, Yamamoto H, Soetikno RM. Endoscopic submucosal dissection of early gastric cancer. J Gastroenterol. 2006;41:929-42.

26. Sasaki T, Tanabe S, Ishido K, Azuma M, Katada C, Higuchi K, et al. Recommended sedation and intraprocedural monitoring for gastric endoscopic submucosal dissection. Dig Endosc. 2013;25(suppl 1):79-85.

27. Chun SY, Kim KO, Park DS, Kim SY, Park JW, Baek IH, et al. Safety and efficacy of deep sedation with propofol alone or combined with midazolam administered by nonanesthesiologist for gastric endoscopic submucosal dissection. Gut Liver. 2012;6:464-70.

28. Akasaka T, Nishida T, Tsutsui S, Michida T, Yamada T, Ogiyama H, et al. Short-term outcomes of endoscopic submucosal dissection (ESD) for early gastric neoplasm: multicenter survey by osaka university ESD study group. Dig Endosc. 2011;23:73-7.

29. Park CH, Lee H, Kim DW, Chung H, Park JC, Shin SK, et al. Clinical safety of endoscopic submucosal dissection compared with surgery in elderly patients with early gastric cancer: a propensity-matched analysis. Gastrointest Endosc. 2014;80:599-609. 